\title{
Chondrocalcinosis after parathyroidectomy*
}

\author{
J. S. GLASS AND R. GRAHAME \\ From Guy's Arthritis Research Unit, Guy's Hospital Medical School, London SEI 9RT
}

Glass, J. S., and Grahame, R. (1976). Annals of the Rheumatic Diseases, 35, 521-525. Chondrocalcinosis after parathyroidectomy. In this retrospective study of 57 patients with primary hyperparathyroidism who underwent parathyroidectomy, the overall incidence of chondrocalcinosis was $\mathbf{4 0} \%$. Neither joint symptoms nor chondrocalcinosis regressed after the operation. In several patients the condition appeared to deteriorate both clinically and radiologically after the operation, while in a few both the chondrocalcinosis and the associated symptoms first appeared some time after the operation.

Hyperparathyroidism is a well established cause of secondary articular chondrocalcinosis and pyrophosphate arthropathy and has been estimated to cause up to $7.5 \%$ of all cases (McCarty, 1966). It is widely believed that persistent hypercalcaemia is the important pathogenetic factor in articular calcification in hyperparathyroidism. Therefore, relief of the hypercalcaemia in such patients by parathyroidectomy might ameliorate the clinical and radiological manifestations of the joints in this condition, or failing that, at least arrest the progress of the chondrocalcinosis which in all other situations appears to be progressive.

The present study investigated to what extent the natural history of chondrocalcinosis secondary to primary hyperparathyroidism is influenced by parathyroidectomy. An attempt was made to determine whether chondrocalcinosis articularis and/or its clinical sequelae diminish, progress, or remain unchanged after parathyroidectomy.

\section{Patients and methods}

Fifty-seven cases of primary hyperparathyroidism underwent surgery in Guy's Hospital between 1952 and 1974. All patients who could be traced were asked to attend hospital again for a clinical, biochemical, and a radiological assessment, which included a detailed history of all joint symptoms and a full clinical examination. Blood was taken for a full blood count; sedimentation rate; plasma calcium, phosphate, alkaline phosphatase, urea, creatinine, and uric acid estimation. $X$-ray of the hands, knees, and (excluding women of child-bearing age) the pelvis, were taken. Those unable to attend were invited to complete a postal questionnaire requesting full details of all joint symptoms occurring before the operation, in the postoperative period, and up to the time that

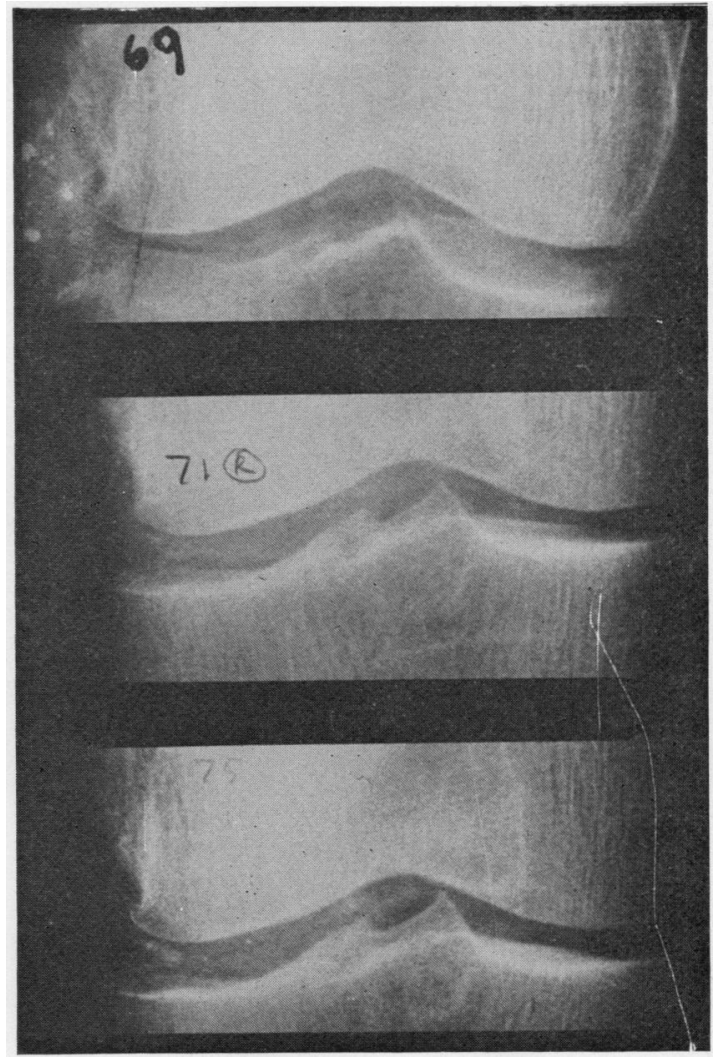

FIG. 1 Case 1. Serial anteroposterior X-rays of right knee between 1969 and 1975, showing increasing calcification of both articular and fibrocartilage 


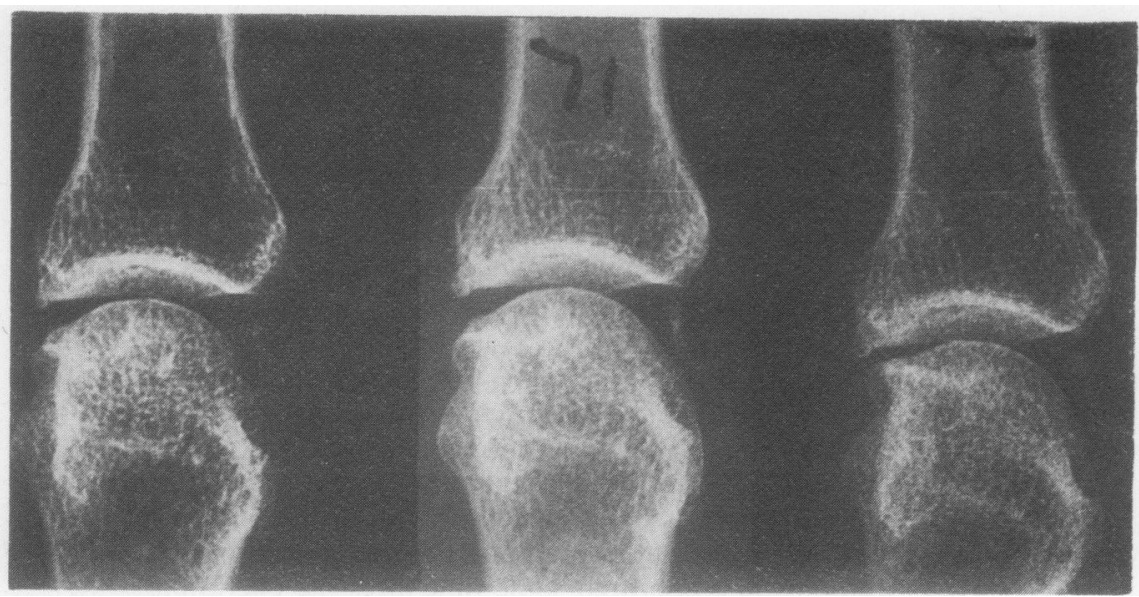

FIG. 2 Case 1. Seria름 anteroposterior $\mathrm{x}$-rays $\overline{\mathrm{c}}$. of right third metacarpophalangeal jointo between 1969 and 1975\% showing progressivechondrocalcinosis 
the survey was conducted, and the date and place of all joint $x$-rays taken before the date of the survey.

\section{Results}

Meaningful comparisons between the preoperative condition and that pertaining at follow-up were possible in respect of $\mathbf{3 0}$ out of $\mathbf{5 7}$ patients as far as joint symptoms were concerned, and in 11 patients in whom the relevant $x$-rays were available. Joint symptoms which were thought to be relevant were recorded in $12(40 \%)$ out of 30 patients. In only 2 of these was there significant improvement after operation; in 5 the situation was unchanged, whereas in the remaining 5 the symptoms had worsened after parathyroidectomy. It must be emphasized that in the majority of cases these symptoms comprised a variety of nonspecific joint aches and pains and in only 3 patients in this series (Cases 1,3 , and 5-see below) was true pyrophosphate arthropathy confirmed by the finding of calcium pyrophosphate dihydrate crystals on polariscopic examination of the synovial exudate. These three attacks all occurred postoperatively-the mean interval from the time of the operation being $3 \cdot 2$ years.

\section{LABORATORY INVESTIGATIONS}

Twenty-six patients agreed to have blood taken for laboratory investigations. Haematological tests were all within the normal range as was the plasma calcium, inorganic phosphate, and alkaline phosphatase in all cases. In 4 patients plasma urate was raised at $11.7,8.4,9.0$, and $7.8 \mathrm{mg} / 100 \mathrm{ml}$ respectively $(0.69,0.5,0.56,0.46 \mathrm{mmol} / \mathrm{l})$. In the former 2 cases this was attributable to renal impairment (blood urea 110 and $102 \mathrm{mg} / 100 \mathrm{ml} ; 18,16.3 \mathrm{mmol} / \mathrm{l}$, respectively), while the latter 2 patients were under treatment for hypertension with oral diuretics.

\section{X-RAY FINDINGS}

Chondrocalcinosis articularis was found at any one time in 14 out of the 35 patients $(40 \%)$ in whom $x$-rays were available. In the 11 patients where comparisons were possible between the preoperative and the postoperative films, in no case was there any discernible reduction in chondrocalcinosis. On the contrary, it had increased in 4 patients and developed initially after operation in 5 . In fact in only 2 patients was there no appreciable change.

\section{CASE HISTORIES}

Four brief case histories give evidence which suggests that chondrocalcinosis either developed or increased after the operation.

\section{Case 1}

A female, born in 1911, presented in 1969 with knee pain and vertebral collapse and was found to be hypercalcaemic $(12 \mathrm{mg} / 100 \mathrm{ml} ; 3 \mathrm{mmol} / \mathrm{l})$ and widespread chondrocalcinosis was present. She underwent parathyroidectomy in 1970 and plasma calcium has remained normal ever since. In 1971 and subsequently in 1975, she was found to have increasing chondrocalcinosis of the knees and hands (Figs. 1 and 2). In 1975 she developed synovitis of the knee and calcium pyrophosphate dihydrate (CPPD) crystals were present in the synovial exhudate.

\section{Case 2}

A male, born in 1931, developed seropositive rheumatoid arthritis in 1966 and in 1971 hyperparathyroidism was diagnosed when he developed a mandibular cyst. Plasma

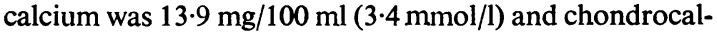
cinosis was noted. Over the next 3 years this was seen to increase (Fig. 3). It was not possible to appraise joint symptomatology in view of his rheumatoid arthritis.

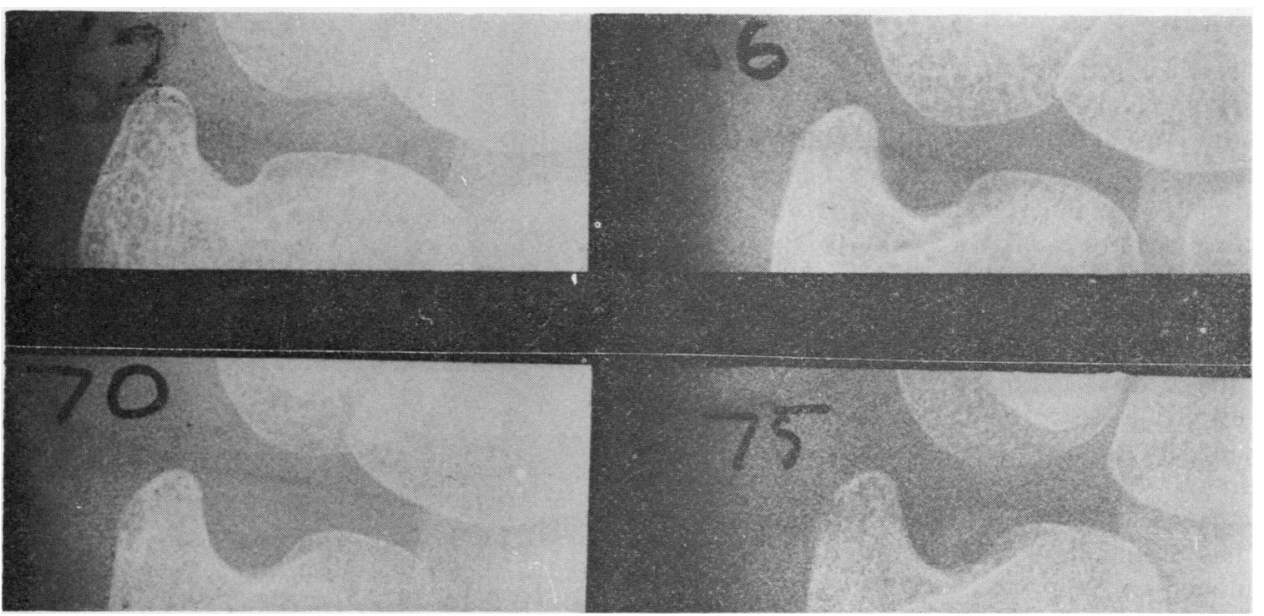

FIG. 4 Case 3. Serial anteroposterior X-rays of the left inferior radioulnar joint between 1962 and 1975. Calcification of the triangular ligament is visible only in the 1975 film 


\section{Case 3}

A female, born in 1913. Hyperparathyroidism was diagnosed in 1962 when she developed swelling of the jaw and nephrocalcinosis was discovered, plasma calcium $14.5 \mathrm{mg} / 100 \mathrm{ml}$ (3.6 mmol/l). Parathyroidectomy was performed and she became normocalcaemic. However, in 1971, because of a rising plasma calcium and urea, a second parathyroidectomy was performed and a second aderoma removed. In 1975 she was seen to have synovitis of the right ankle and knee and chondrocalcinosis was observed for the first time, i.e. 4 years after the second operation (Fig. 4). CPPD crystals were found in the synovial fluid.

\section{Case 4}

A female, born in 1910, developed renal calculi in 1971 and was found to be hypercalcaemic (calcium $11.5 \mathrm{mg}$ / $100 \mathrm{ml} ; 2.9 \mathrm{mmol} / \mathrm{l}$ ). Parathyroidectomy was performed and plasma calcium returned to normal. In 1973 she complained of pain in the right wrist and chondrocalcinosis was observed in the triangular ligament of the right inferior radioulnar joint and a destructive lesion was seen in the adjacent carpal bone (Fig. 5).

\section{Case 5}

A female, born in 1920, presented in 1974 with a 7-year history of episodic pain, stiffness, and swelling of the wrists and knees. Widespread chondrocalcinosis was noted in the knees, hands, and shoulders. Hyperparathyroidism was diagnosed on the basis of hypercalcaemia: plasma calcium $11.8 \mathrm{mg} / 100 \mathrm{ml}(2.95 \mathrm{mmol} / \mathrm{l})$; plasma phosphate $2.2 \mathrm{mg} / 100 \mathrm{ml}(0.7 \mathrm{mmol} / \mathrm{l})$; and plasma parathormone $1.28 \mathrm{ng} / \mathrm{ml}$ (normal 0.9). She underwent parathyroidectomy on November 14, 1974. One month later she suffered an attack of pyrophosphate arthropathy on the left knee which was confirmed by polarizing microscopy. 16 months after operation she still complained of similar symptoms affecting her wrists and knees which appeared to be more severe than before the operation. There appears to be an increase in the chondrocalcinosis as seen on $x$-ray.

\section{Discussion}

The short-comings of a retrospective study of this kind are self-evident. Many of the patients in the original series in the present study were not available for follow-up and clinical data concerning many of the earlier patients who underwent parathyroidectomy were scanty. Many $x$-rays relevant to the present study were either not available or inadequate so no meaningful comparison could be made with those taken at follow-up. Nevertheless, certain observations on the natural history of chondrocalcinosis after parathyroidectomy were possible. For example, the finding of chondrocalcinosis articularis at any one time in $14(40 \%)$ of 35 patients in whom $x$-rays were available is a considerably higher incidence than has been previously reported. In Dodds and Steinbach's (1968) series of 91 cases, $18 \%$ showed chondrocalcinosis, while in a series by Mallette and others (1974) only $8.8 \%$ of the 57 patients showed this abnormality.
The major interest of the study, however, lies in the hitherto unreported failure of joint symptoms to improve after parathyroidectomy. Arthralgia is known to occur in hyperparathyroidism and usually affects the small joints of the hand, the knees, ankles, elbows, or hips, and may be accompanied by morning stiffness (Mallette and others, 1974). Acute synovitis due to pyrophosphate arthropathy is a distinctly rarer phenomenon which is believed to

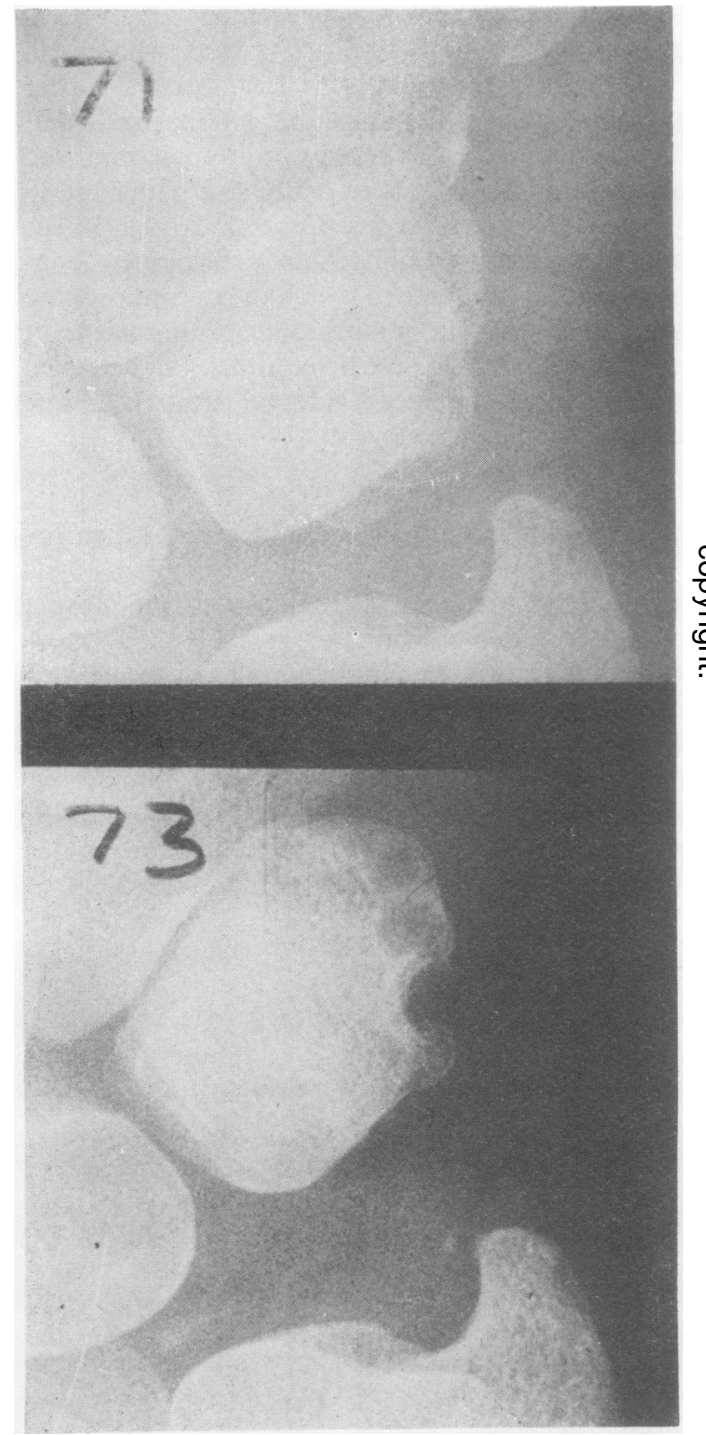

FIG. 5 Case 4. Serial X-rays of right inferior radioulnar $\mathbb{\mathscr { D }}$ joint between 1971 and 1973. Calcification of the triangular? ligament is visible in the 1973 film. A destructive lesion has 7 appeared in the adjacent triquetral bone whick was not present in 1971. Such lesions have been described by Resnick ${ }_{\bigcirc}^{\mathbb{D}}$ (1974) 
occur, particularly in the postoperative period after parathyroidectomy (Bilezikian and others (1973). In this series pyrophosphate arthropathy occurred for certain in only three instances and much later after the operation (mean 3.2 years). The reason why joint symptoms failed to improve after the operation (and in many cases worsened) could be explained by the progression of the chondrocalcinosis in several patients in the series. This finding itself is surprising in view of the normocalcaemia that all these patients showed from the time of their operation. A possible explanation is that once a nidus of CPPD crystals has been formed by the process of metastatic calcification in cartilage during the hypercalcaemic phase, further accretion takes place, even when hypercalcaemia no longer exists.

In a previous study (Grahame, Sutor, and Mitchener, 1971) we drew attention to the intimate relationship between CPPD crystals and sodium urate in the articular tissues of a patient with hyperparathyroidism who also suffered from hyperuricaemia and gout, and suggested that perhaps prior precipitation of one kind of crystal might affect the local tissue environment within the cartilage in such a way as to favour the precipitation of the other kind. However, it seems unlikely that this factor could explain the persistence or progression of the chondrocalcinosis in the present series, since hyperuricaemia was excluded at follow-up in all but 4 patients none of whom suffered from clinical gout.

We conclude that whereas parathyroidectomy is capable of reversing most of the clinical and biochemical features of primary hyperparathyroidism, this is not so in the case of articular symptoms and chondrocalcinosis, both of which may persist or even worsen after the operation. It is suggested that patients undergoing parathyroidectomy for hyperparathyroidism who suffer from joint complaints should be warned of this possible eventuality.

We are indebted to Mr. Noel Glover, FRCS, for permission to study the patients in this series all of whom were under his care.

\section{References}

Bilezikian, J. P., Connor, D. B., Aptkar, R., Freijanes, J., Burbach, D. G., Paches, W. N., Wells, S. A., and DECKER, J. R. (1973) Lancet, 1, 7801 (Pseudo-gout after parathyroidectomy)

Dodds, W. J., AND Steinbach, H. L. (1968) Amer. J. Roentgenol; 104, 884 (Hyperparathyroidism and articular cartilage calcification)

Grahame, R., Sutor, D. J., And Mitchener, M. P. (1971) Ann rheum. Dis., 30, 597 (Crystal deposition in hyperparathyroidism)

MCCARTY, D. J. (1966) 'Crystal deposition disease-calcium pyrophosphate' in 'Modern Trends in Rheumatology I', ed. A. G. S. Hill, p. 287. Butterworths, London

Mallette, L. E., Bilezikian, J. P., Heath, E. A., and Aurbach, B. D. (1974) Medicine, 53, 127 (Primary hyperparathyroidism; clinical and biochemical features)

RESNICK, D. L. (1974) Radiology, 110, 263 (Erosive arthritis of the hand and wrist in hyperparathyroidism) 